ISSN: 2162-3104 Print/ ISSN: 2166-3750 Online

Volume 6, Issue 2 (2016), pp. I-X

(C) Journal of International Students http://jistudents.org/

\title{
(Re)Examining the Research on International Students: Where Are We Today?
}

\author{
Krishna Bista \\ University of Louisiana at Monroe (USA)
}

\section{What Defines International Students?}

A working definition of an international student, as Shapiro, Farrelly and Tomas (2014) acknowledged, is "a student who moves to another country (the host country) for the purpose of pursuing tertiary or higher education e.g., college or university" (p.2). The United States Citizenship and Immigration Services (USCIS) defines an international student as: "Anyone who is enrolled at an institution of higher education in the United States who is not a U.S. citizen, an immigrant (permanent resident) or a refugee" (2015, para 2).

The term "international student" is a temporary identity for all mobile students. However, the definition and other inclusion/exclusion criteria for international students may be different in many countries. Once international students complete their studies, go back to their home country, or start working overseas on a different visa status, the temporary identity as an international student goes away (Bista \& Foster, 2016).

In the context of US higher education, there are many terminologies that classify international students. Some examples are foreign students, non-immigrant students, mobile students, transnational students, inbound/outbound students, guest students, and so on. Today, there is no precise definition of what an international 
students is. de Wit (2016, p. xvii) illustrates this problem in the following passage.

There is interesting debate to be held about what in the current complex global environment is meant by 'international student'. For instance, is a Malaysian student studying in Malaysia at a branch campus or a franchise operation of an Australian university, a local or an international student? The student is studying towards an international degree, at an international institution, which makes her an international student. However, she is a student in her own country and counted as such in Malaysia's higher education statistics which makes her a local student. And if a Malaysian student takes part in a $2+2$ twinning program, is that student first a local student and in her last two years an international student? Or if that student took an online degree program of an Australian university, would she count as a local student given her location - or - given the degree - would she count as an international student?

In the context of international education, the role of international students is well noted in academic, political, social, and cultural discourses. Scholars and educators have discussed experiences, challenges and opportunities resulting from having the presence of international students in the institutions of higher education. Today, the United States, the United Kingdom, Australia, Canada and New Zealand are the top destinations for international students. In the 2014/2015 academic year, the number of international students at US colleges and universities reached to 974,926 students (Institute of International Education, 2015). Students from India and Brazil showed the largest increases in US data. While data from Latin America shows it is the fastest growing region internationally. China, India, and South Korea are the top three countries sending international students to US colleges and universities. According to the Open Doors 2015 report, international students constituted almost five percent of 20 million students enrolled in US higher education.

A majority of international students study business, engineering, math/computer science, and physical/life sciences in the 
US. According to the Open Doors 2015 report, the top US institutions hosting more than 10,000 international students are New York University $(13,178)$, the University of Southern California $(12,334)$, Columbia University $(11,510)$, Arizona State University $(11,330)$, the University of Illinois, Urbana-Champaign (11,223), Northeastern University $(10,559)$, Purdue University, West Lafayette $(10,230)$, and the University of California, Los Angeles (10,209). Among all international students, there were $40.9 \%$ undergraduate students, 37.2 $\%$ graduate students, and $9.6 \%$ non-degree students in the $2014 / 2015$ academic year.

\section{New Trends and Changes}

In the United States, 58\% of international students came from China, India, South Korea, and Saudi Arabia in the 2014/2015 academic year.

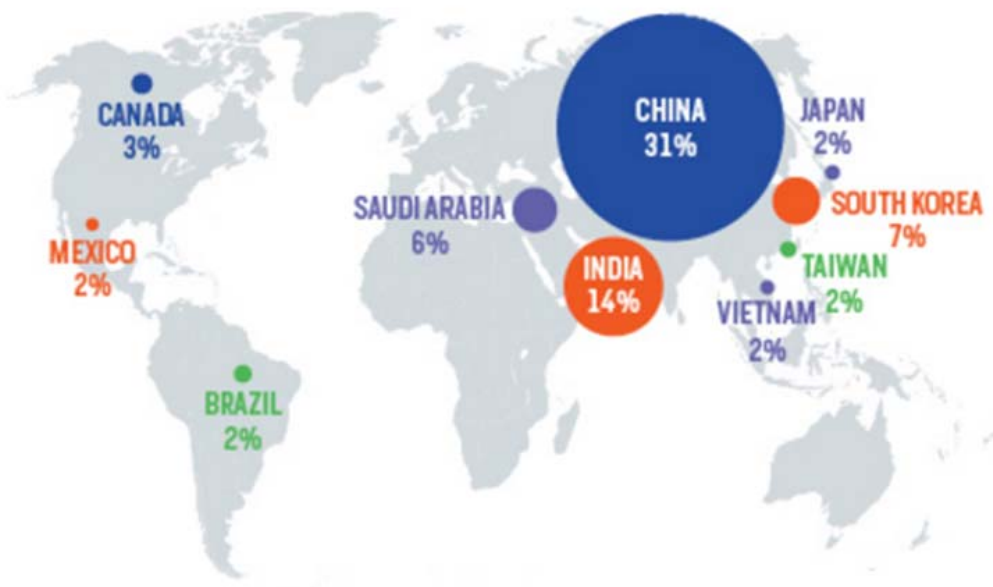

\section{International Student Population}

International students make up a greater percentage of the overall U.S. student population than ever before, and their numbers are rising rapidly.

Source: Institute of International Education Open Doors 2015

International students contributed $\$ 30.8$ billion to the U.S. economy in the 2014/2015 academic year. For these students, the primary sources of funding were personal and family resources (64\%), scholarships and fellowships from American colleges (21\%), 
and support from foreign governments or universities (8\%). With their expenses from education, accommodation, dining, transportation, and health insurance, 37,338 jobs were created and supported in the 2014/2015 academic year (NAFSA, 2015).

\section{Financial Contributions by State}

International student tuition fee is at least two or three times higher than the state or local student fee. In addition to paying full tuition, international students also help feed the economy by spending on housing and other goods. California, New York, Massachusetts, Pennsylvania, and Texas are the major states that received the biggest financial contributions from international students in 2014/2015.

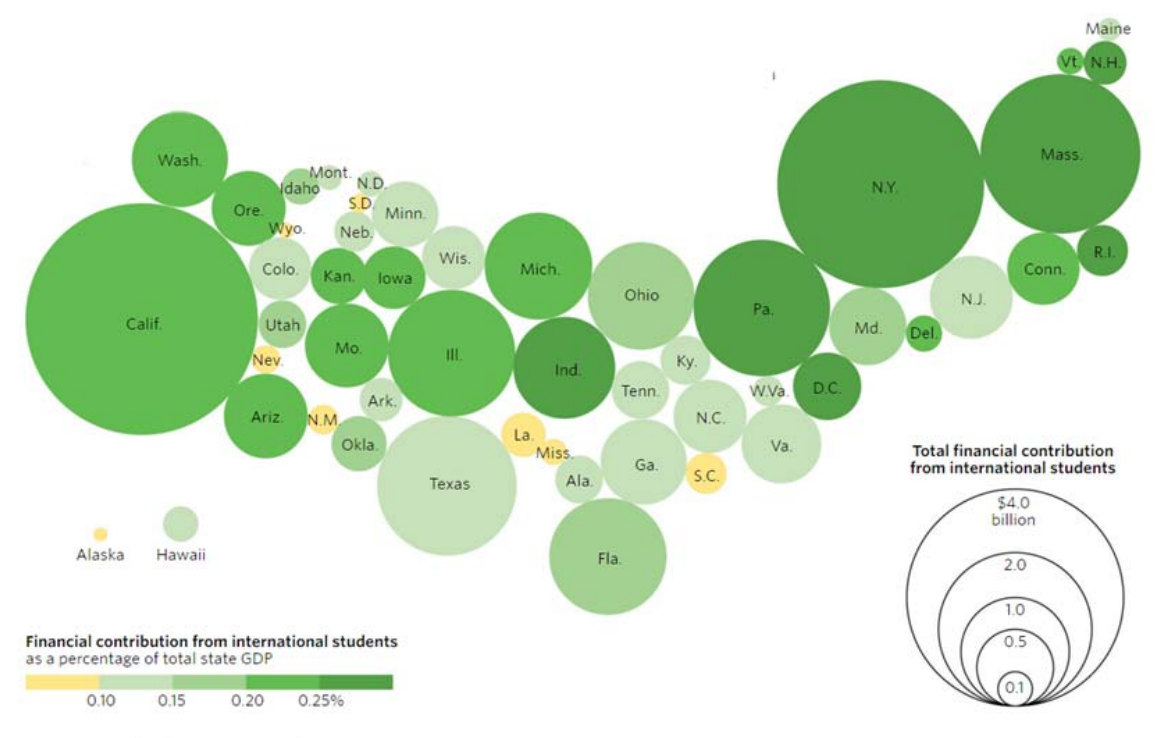

Note: Data are for the 2014-2015 academic year

Source: NAFSA: Association of International Educators and Commerce Department

\section{Research on International Students: Growing Field?}

International students represent a major segment of college student population with a distinguished identity and status, yet they are not so different from domestic or local students in terms of college access and success. Scholars interested in the field of international students have researched on a variety of topics. International students, 
who leave their countries of origin and go to another country to pursue further studies, undergo a number of challenges to adjust to new social and academic environments. Previous research studies have focused on international students' academic and social aspects of college experiences, their cultural differences and the adjustment process, college access and success, and academic careers after the completion of degree programs. When I searched the keywords "international student" in the Google Scholar all time collection, 120,000 results were shown in 0.04 second. The same search engine showed 12,500 results since 2015. Similarly, the Google search showed 218,000 results in 0.26 second when I used the keywords "Journal of International Students". These results suggest there are numerous documents written and published related to international students

As an educator interested in international student research, I am curious about the nature of existing studies in this field. Using the University of Florida's library access, I searched the keywords "international student" in four major databases (ProQuest journals, ProQuest Dissertations, EBSCOhost, and ERIC). There were two reasons for doing this. First, international student research usually falls under education and social science research. Second, ProQuest, ERIC, and EBSCOhost are professional and reliable databases that collect a vast majority of journals from multiple disciplines.

1. ProQuest Education Journals: This is one of the largest collections of journals, newspapers, dissertations/theses, magazines, books, and reports. This database contains 11,953 results from 1957 to 2016 when searched using the keywords "international students". Over 4,000 of these results were newspaper articles (published in university websites, The Times Higher Education Supplement, International Educator) related to international students. When I narrowed the search to include only results from 2015-2016, there were 2,999 results related to international students with 363 peer-reviewed journal articles, of which 169 were related to the Journal of International Students. The majority of these reports, news, and articles were US-based. However, there were still many publications from China, South Korea, India, and other countries. In the past 15 months, some of 
the professional academic journals that published international student related articles were: Journal of International Students (35 counts), International Education Studies (13 counts), International Review of Education (9 counts), and Diverse Issues in Higher Education (5 counts) to name a few. Such counts may be inaccurate or the articles may not be updated in the data bases as articles get published.

2. ProQuest Dissertations \& Theses Global: This is an excellent database that collects graduate theses and dissertations from the universities located in the United States and Canada. In its entirety, this database contains 1,403 results related to international students with 1,220 full texts. In separate manual search, I read the titles of the doctoral dissertations published in the last twelve months (January - December 2015). I found 100 doctoral dissertations on "international students." These dissertations were published on a variety of topics from American and Canadian universities (a full reference is provided at the end of this volume).

3. EBSCOhost (all databases): Searching from 1908 to present, EBSCOhost (all databases) shows 12,801 results related to "international student." There were 1,341 results on this topic since 2015. This database listed 289 journal articles and 247 reports on international education that include the term "international student."

4. ERIC: The Education Resources Information Center (ERIC) is an online digital library of education research that provides access to 1.5 million records. This database contains 3,043 results since 1997. There were 308 records related to international students. Of these, 172 results were related to "foreign students" in the past 15 months. ERIC categorized the fields of the collections as: Postsecondary Education (158), Higher Education (155), Two-Year Colleges (6), and High School (1). 
These existing materials suggest that on average, there are at least 8 doctoral dissertations and theses, 200 reports/newspaper articles, and 10 journal articles written and published every month. Although the topic of international students is a growing field with limited articles and new reports, it has substantially contributed to the field of international education. Scholars and educators are writing and publishing in this field at an increasing rate.

Taylor and Francis, a UK-based international publishing company established in 1852, publishes 2,681 journals on a various disciplines. While searching on its journal website, I found 5,510 articles or chapters that contain the term "international student." Within its 900 professional journals in various disciplines, Sage Publications, an independent publishing company founded in 1965, showed 2,347 results that contained the term "international student." This information also indicates that there are plenty of publications focused on diverse issues of international students. Authors from multiple disciplines have examined the academic, social, psychological, and other aspects of this student population.

\section{Synopsis of Articles Included in the Volume}

In this volume, 35 authors, who represented several institutions of higher education, have shared their perspectives and research findings (both quantitative and qualitative) based on their experiences in Canada, China, Japan, Saudi Arabia, the United Kingdom, and the United States. Each article is rich in term of cross cultural perspectives of mobile students, their learning experiences, and campus diversity.

In his article, Takahiro Sato described Asian international doctoral students' sojourn experiences at two American universities. The emergent themes from his study were (a) research challenges; (b) academic, social, and hierarchical relationships with doctoral advisors; (c) burnout; and (d) situation-specific anxiety. In next article, Zachary S. Ritter interviewed 47 international students to study racial stereotypes and socio-economic status hierarchies that may affect campus climate. His study indicated that a majority of students had racial and status hierarchies and harbored prejudices toward African-Americans and Southeast Asians. 
Rui M. Schroeder developed the Academic Spoken English Strategies Survey (ASESS). Jamie Harrison and Hong Shi presented an exploratory conversation between a professor and her graduate student taking the methods and materials course.

Soonhyang Kim and colleagues examined the role of silence and found that the use of silence by Japanese students varied on a highly individualized basis, not only by culture. They suggested that silence can be used as a form of engaged learning and active participation. Fei Wang's study revealed that Canadian-born Chinese students differed from their foreign-born counterparts in their viewpoints on ethnic identity; their perceptions concerning acculturation; and academic performance. His participants shared similarities in their views about Canadian and Chinese educational systems, teaching styles, and their career expectations.

Katherine Punteney's survey research revealed that key factors motivating students in international careers included love of travel, interest in other cultures, the possibility of earning a high salary, and the potential for opportunities in the major discipline. Key concerns included leaving family and friends and a lack of foreign language ability.

Chetanath Gautam and his team studied international students' experiences and their challenges in the US. Based on in-depth interviews, they found the major challenges of international students were language, jobs/finances, transportation, assimilation, religious interactions, and identity. In her article, Danielle Geary explored some of the challenges international students face and suggests ideas for sparking interaction between international students and Americans.

Daniel Adrian Doss and his team examined students' perceptions of plagiarism as evil and illegal activities. Donna M Velliaris and Paul Breen focused on academic staff identification and remediation processes for the prevention of (un)intentional student plagiarism.

In their research, Elizabeth Frances Caldwell and Denis Hyams-Ssekasi explored the preparations of Black-African students for leaving their home countries to study abroad. Participants in their research shared the complex and frustrating process of obtaining visas 
and applying to university abroad, tensions of leaving their communities and difficulty to adjust in their host institution.

The study of Per A. Nilsson and Nannette Ripmeester showed that the transition from education to the world of work is of increasing importance for international students. How to find a job upon graduation is apparently a big concern for current-day students, which dictates their international educational choices to a large extent. Heather Campbell and colleagues addressed the current landscape of the globalized western classroom and discussed current pedagogical challenges in communication courses from the perspective of communication instructors. Prashanti Chennamsetti reviewed a recent book International Students and Crime, which investigates the phenomenon of international student crime using qualitative methodology.

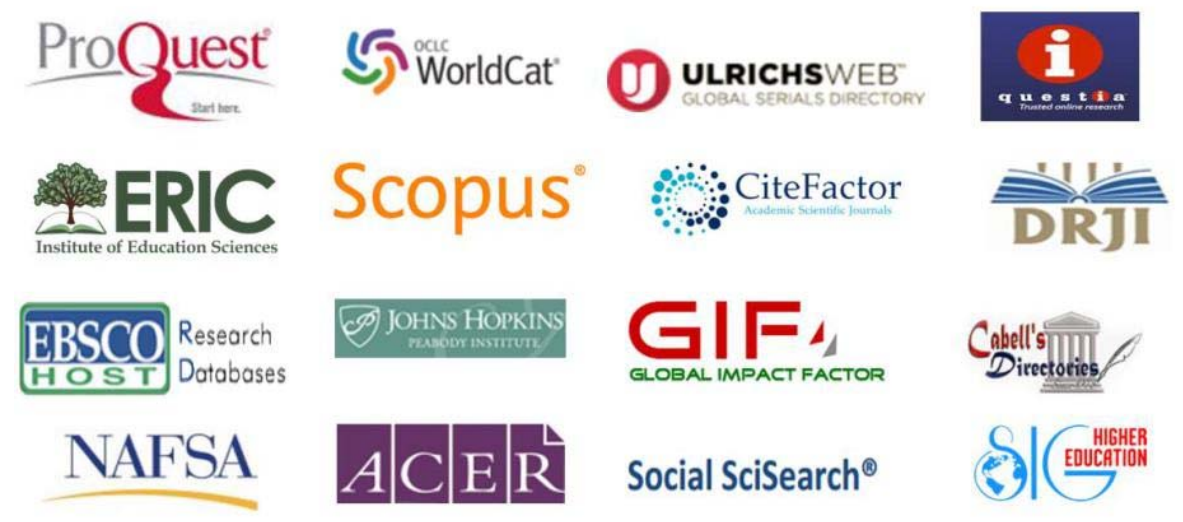

All articles from the Journal of International Students are indexed and listed in major databases and sources.

\section{Final Thought}

As in our previous volumes, this current edition also includes a wide variety of articles written by faculty members and doctoral students from various institutions and countries. We believe that educators, policy makers, administrators, teachers, students and individuals interested in mobile student affairs, study abroad, crosscultural studies and international education, from across the globe, 
can take advantages of reading these articles published in this volume!

Altogether, we believe that scholarly articles of this volume from various disciplines will contribute positively to the field of international student studies. As in the past, we have continued our tradition of sharing free digital copies with students, faculty members and libraries in the United States and abroad. Finally, I would like to thank the reviewers, copy editors, assistant editors, editors, and our board of directors for their voluntary contributions to the Journal

Happy reading!

\section{REFERENCES}

Bista, K., \& Foster, C. (eds.). (2016). Global perspectives and local challenges surrounding international student mobility. Hershey, PA: IGI Global.

de Wit, H. (2016). Forward. In Bista, K., \& Foster, C. (eds.) Campus support services, programs, and policies for international students (pp. xvii-xviii). Hersey, PA: IGI Global.

Institute of International Education (2015). http://www.iie.org/ /media/Images/Corporate/Other/Open-Doors2015/Infographic-Open-Doors-2015-InternationalStudents.jpg?la=en

NAFSA (2015). http://www.nafsa.org/Explore_International _Education/Impact/Data_And_Statistics/NAFSA International_Student_Economic_Value_Tool/\#stateData

Shapiro, S., Farrelly, R., \& Tomas, Z. (2014). Fostering international student success in higher education. Alexandria, VR: TESOL press.

USCIS. (2015). The United States Citizenship and Immigration Services. Retrieved from https://www.uscis.gov/tools/glossary 